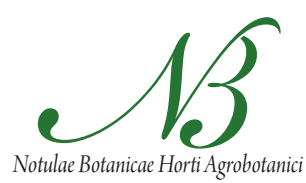

Cluj-Napoca

\title{
Dark-chilling of Seedlings Affects Initiation and Morphology of Broccoli Inflorescence
}

\author{
Aneta GRABOWSKA', Agnieszka SĘKARA *, Monika \\ BIENIASZ², Edward KUNICKI', Andrzej KALISZ \\ ${ }^{1}$ University of Agriculture in Krakow, Department of Vegetable and Medicinal Plants, 29-Listopada \\ 54,31-425 Kraków, Poland; a.sekara@ur.krakow.pl (*correspondingauthor) \\ ${ }^{2}$ University of Agriculture in Krakow, Department of Pomology and Apiculture, 29-Listopada 54, 31-425 Kraków, Poland
}

\begin{abstract}
The constant supply of broccoli heads for a vegetable market can be kept by the differentiation of sowing time and the age of seedlings. Dark-chilling of young seedlings can also modify the time of transplanting, subsequent plant development, yield and inflorescence quality. The aim of the present study was to analyze the influence of seedling dark-chilling on the inflorescence initiation and the morphological quality of broccoli heads. The experiment was carried out at the University of Agriculture in Krakow (South Poland) in the years 2009 and 2010, with broccoli (Brassica oleracea L. var. italica Plenck) medium late cultivar 'Monaco' $F_{1}$. The examined factors were the age of seedlings (4-, 6-, 8-, and 10-week-old) and dark-chilling $\left(2^{\circ} \mathrm{C} / 2\right.$ weeks and non-chilled control). Microscopic analysis of the apex sections was performed to determine the time of the inflorescence differentiation in chilled and non-chilled seedlings of different age. Chosen morphological features of the mature heads were also described as depended on age and chilling of seedlings. The inflorescence initiation was observed between 4 and 6 week of the plant ontogeny. Especially 4-week-old seedlings, chilled by two weeks, were more advanced in the generative development in comparison to non-chilled control. Low temperature applied in the seedling stage did not cause the head buttoning. Inflorescences developed by broccoli planted from 4 and 6-week-old seedlings, both chilled and control, were characterized by the best visual quality, determined by a convex head shape, tight branching angle, small and uniform size and regular form of flower buds. Chilling of oldest, 8 - and 10-week-old seedlings negatively affected the inflorescence quality, through planed and spread shape of heads and non-uniform shape of flower buds.
\end{abstract}

Keywords: Brassica oleracea L. var. italica, head quality, morphogenesis

\section{Introduction}

The requirements of the fresh vegetable market as well as the processing industry increase continuously with respect to the quality, diversity and continuity of product supply. Environmental conditions in Poland enable to grow broccoli in the field from spring to autumn. The continuity of broccoli supply for the fresh market and processing industry is possible by differentiation of the date of sowing and age of seedlings. Latest investigations of Grabowska et al. (2007a, b) allow concluding that seedlings can be subjected to dark-chilling in order to modify the time of transplanting, yield level and inflorescence quality.

The inflorescence initiation is the most important phase of the broccoli ontogeny. The exact determination of the vegetative stage beginning allows to precise apply of cultivation practices and leads to optimization of the yield and its quality. Grevsen (1998) found that the initiation of the broccoli head followed a stage of least seven visible leaves or a total of 14 leaves were formed. Björkman and Pearson (1998) compared the external appear- ance of broccoli shoot tip with the microscopic appearance of the meristem during the reproductive transition. They found that the shoot tip remains $4-5 \mathrm{~mm}$ across during the vegetative stage and the increase of its measurement to $6 \mathrm{~mm}$ together with change of the youngest leaves' shape is associated with the transition to the generative stage. Grevsen and Olesen (1999) found that the transition to the generative phase and the curd formation in broccoli take place in the temperature between 9.9 and $22.3^{\circ} \mathrm{C}$, with optimum of $16.1^{\circ} \mathrm{C}$. They defined the head initiation as the time when the apex diameter reaches $0.6 \mathrm{~mm}$, although Kałużewicz et al. (2002) observed the initial generative phase at apex diameter of $375 \mu \mathrm{m}$. The length of the vegetative phase depended on a cultivar and term of cultivation, and temperature was specified as the main environmental factor affecting the beginning of inflorescence initiation (Fujime, 1988; Grevsen and Olesen, 1999; Kałużewicz et al., 2002, 2010; Mourao and Brito, 2000; Tan et al., 2000). Low temperature is a common factor determining the plant transition from the vegetative to generative stage of growth. Miller $e t$ al. (1985) in- 
214

vestigated this phenomenon in broccoli. Authors stressed that 6 to 33-day-old seedlings exposed to $-3,-5,+1$ and $+2^{\circ} \mathrm{C}$ during 7 to 34 days induced flowering earlier than untreated plants. In broccoli cultivation, chilling of seedlings found to be an important way to stimulate the inflorescence initiation. Uncontrolled and too early action of low temperature can result in forming premature heads, so called buttoning, which significantly decreases the marketable yield. Too little or too much hardening, cold weather for more than 10 days at 4 to $10^{\circ} \mathrm{C}$, diseases, insects and micronutrient deficiencies have been reported to cause buttoning (Fritz et al., 2009). According to Masarirambi et al. (2011), minimization of transplant shock and maximization of conditions which favor vegetative growth can reduce the occurrence of this disorder. Chilling of the plants in the juvenile phase is a method to induce tolerance mechanisms against several abiotic stresses. It may lead to improve the yield level and its quality. Grabowska et al. (2007a) obtained a significantly higher yield of broccoli heads from seedlings dark-chilled at $2^{\circ} \mathrm{C}$ during two weeks as compared to non-chilled control. Chilling of broccoli seedlings also influenced the chemical composition of mature heads (Grabowska et al., 2007b). Therefore dark-chilling of seedlings can be conducted together with seedling storage in controlled conditions in market transplant production. Described preliminary studies allow to form a question on the effect of dark-chilling during juvenile phase of growth on subsequent broccoli development and inflorescence morphology, which dependence have not been widely discussed in world literature yet.

The aim of the present investigations was the analysis of the influence of seedling dark-chilling on the generative development of broccoli plants and the visual quality of heads.

\section{Materials and methods}

\section{Experiment design}

The experiment was carried out at the University of Agriculture in Krakow (South Poland) in the years 2009 and 2010, with broccoli (Brassica oleracea L. var. italica Plenck) medium late cultivar 'Monaco' $F_{1}$. The examined factors were the age of seedlings (4-, 6-, 8-, and 10-weekold) and dark-chilling $\left(2^{\circ} \mathrm{C} / 2\right.$ weeks) while 2 weeks at optimal temperature was considered as the control. The experiment was set in the random block design in four replications. The seeds were sown to multipots PV 96, seedlings were grown in a greenhouse. Dates of seed sowing were calculated to obtain seedlings of different age (4, 6,8 , and 10 -week-old), which were an initial material. On 26 June 2009 and 18 June 2010 part of the initial material was placed in a cold room and treated with dark-chilling: $2^{\circ} \mathrm{C}$ for 2 weeks, RH 95\%, in darkness. The second part of initial material was the control, which was grown in a greenhouse for 2 weeks. On 11 July 2009 and 1 July 2010 chilled and control seedlings were planted out in the ex- perimental field in spacing $67.5 \times 40 \mathrm{~cm}$. The agronomic treatments were applied in accordance with the requirements of the species.

\section{Inflorescence initiation assessment}

The shoot tips of 10 plants from each experimental object were collected on 27 June 2009, 18 June 2010 (shoot tips of 4, 6, 8 and 10-week-old seedlings - initial material), 11 July 2009 and 1 July 2010 (shoot tips of 4, 6, 8 and 10-week-old seedlings chilled during 2 weeks and non chilled control). The Björkman and Pearson (1998) modified method was used to determine the stage of apex development on a base of its external appearance, as well as the size of shot tips. Analyzed shoot tips were divided into 4 groups corresponding with 4 stages of reproductive transition: (a) vegetative stage, apex meristem with leaf primordia, (b) beginning of the generative stage, straightened shoot tip, bract primordia with a flat spot at the incipient axillary meristem, (c) bowed stage, higher order meristems are now differentiated from branch to floral primordia, (d) headed stage, floral buds developing on floral stalks.

Ten shoot tips from each treatment were fixed in Carnoy's solution (ethanol : acetic acid 3:1, v/v), dehydrated with $80 \%$ ethanol, than embedded in paraffin. Sections of $8 \mu \mathrm{m}$ thickness were contrasted with iron-ammonium alum and observed with microscope Axioimager 2 (Carl Zeiss AG, Germany) to observe the stage of inflorescence initiation.

\section{Morphological quality assessment}

The 10 inflorescences in a stage of harvest maturity were collected from each experimental object on $23 \mathrm{Au}$ gust 2009 and 16 August 2010 (inflorescences developed by plants from 10-week-old seedlings); 27 August 2009 and 23 August 2010 (8-week-old seedlings); 3 September 2009 and 30 August 2010 (6-week-old seedlings); 8 September 2009 and 3 September 2010 (4-week-old seedlings). The inflorescence diameter along the head surface was measured. The inflorescence quality parameters were assessed according to the 5-point scale proposed by Tan $e t$ al. (1999): head shape ranged from convex (5) to concave (1); branching angle - tight (5) to spreading (1); and bud color - dark green (5) to pale green (1). Attribute ratings of 1 were unmarketable, and of 5 - highly marketable.

The flower buds of each inflorescence were observed with a stereomicroscope SteREO Lumar V12 (Carl Zeiss AG, Germany) to determine its quality. The diameter and stalk length of successive flower buds on an oldest outward-facing whorl on the third branch were measured. According to Björkman and Pearson (1998), the size of these buds is consistent and representative of the quality of a whole curd. The measurements were made with a use of Image Tool for Windows 3.0 software, after registration of the image with a use of a SteREO LUMAR V12 microscope (Carl Zeiss AG, Germany). 


\section{Results and discussion}

The initiation of an inflorescence morphogenesis is an important phase of broccoli ontogeny, depending on the age of plants and environmental factors, mainly temperature (Fujime and Okuda, 1996). In the conditions of the presented experiment, the 4-week-old seedlings of initial material did not begin the generative phase development - all observed apexes were in a vegetative phase of growth (Fig. 1).

This phase was characterized by small and pointed apical meristem surrounded by leaf primordia. Such form of a shot tip is typical for vegetative stage of broccoli development (Tan et al., 1998). After next two weeks of control and chilling conditions only 23 and $9 \%$ of seedlings, respectively, remained in the vegetative phase. The initiation of the inflorescence morphogenesis was observed in 6 -week-old seedlings of initial material, where $15 \%$ of apexes were in the straightened stage, with wide leaf primordia and a flat spot at the incipient axillary meristem. After next two weeks of control or chilling conditions the apex was in a generative phase, characterized by the wide and flattered shape with initials of floral stalks and florets, surrounded by strongly bent cover leaves (Fig. 1 and 2). Similarly formed broccoli apexes were described as a late developed stage by Kałużewicz et al. (2002). 8and 10-week-old seedlings reached a generative phase of growth with a curd visible in a macroscopic scale before chilling (Fig. 3).
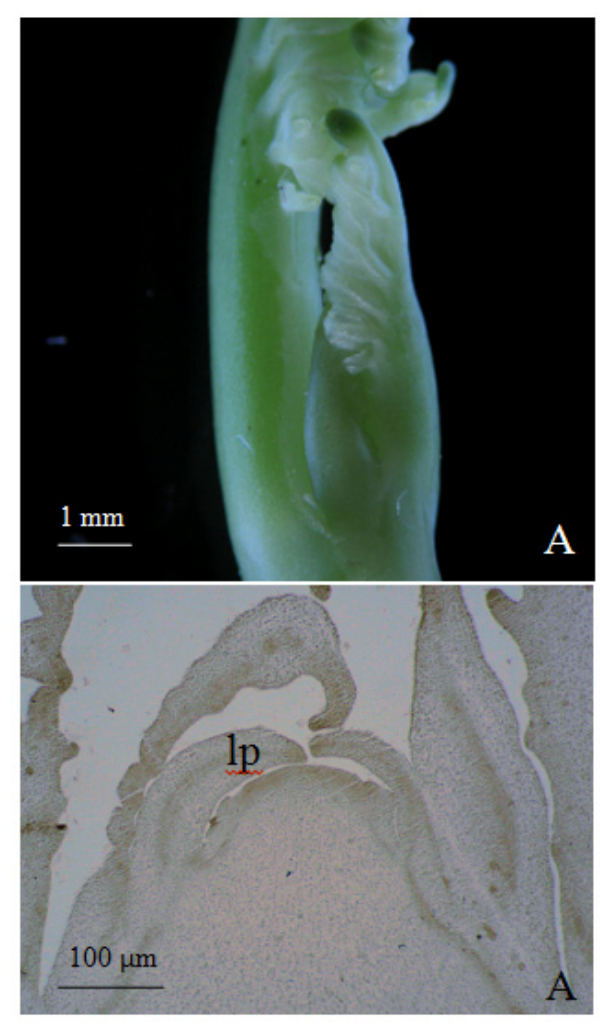

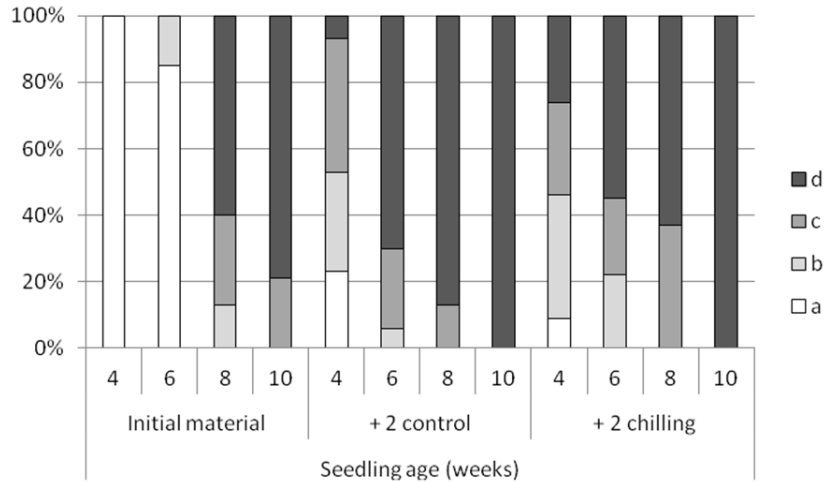

Fig. 1. Percent of apexes in particular stage of development (a) vegetative stage, (b-d) successive stages of a generative phase: b - straightened stage, bract primordia with a flat spot at the incipient axillary meristem, $\mathrm{c}$ - bowed stage, higher order meristems are now differentiated from branch to floral primordia, $\mathrm{d}$ - headed stage, floral buds developing on floral stalks

In this stage, inflorescence development was slower in plants exposed to chilling as compared to non-chilled control. Fujime (1988) stressed that the response of broccoli seedlings to low temperature depended on a cultivar and phase of development. Based on the research on cauliflower, Wurr et al. (1981) postulated that the phase of growth during which the curd-initiation period can be shortened by cold treatment $\left(0^{\circ} \mathrm{C}\right.$ for 15 days $)$ is specific for a cultivar and a receptive phase occurs at higher leaf-numbers with cultivars which take longer to initiate curds. In the manner proposed, chilling of 4-week-old seedlings increased

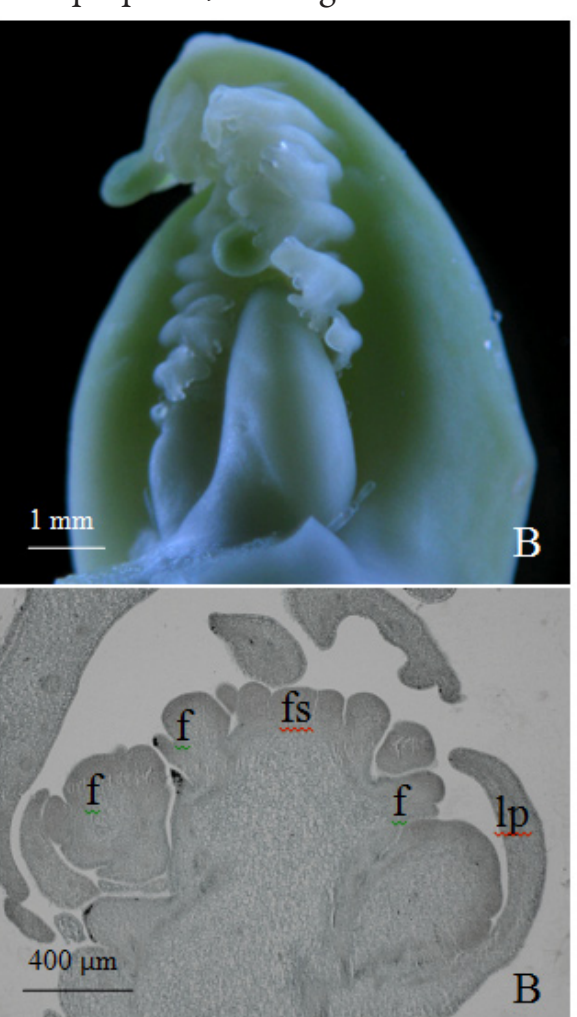

Fig. 2. The apex of 6-week-old seedlings before chilling (A) and after 2 weeks of chilling in $2^{\circ} \mathrm{C}(\mathrm{B})$ : lp-leaf primordium, fs-floral stalk, f-floret 

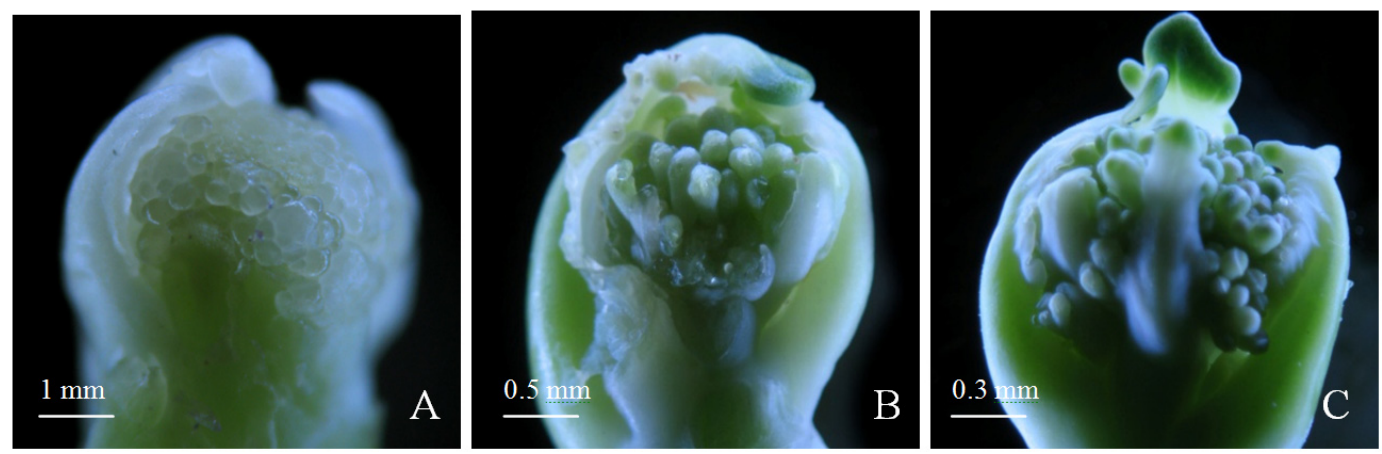

Fig. 3. Inflorescence formation in 10-week-old seedlings before chilling (A) and after 2 weeks of chilling in $2^{\circ} \mathrm{C}(\mathrm{B})$ and after two weeks of control temperature $(\mathrm{C})$

the percent of plants in a generative phase as compared to non-chilled control, whereas Kałużewicz et al. (2002) observed the initiation of a generative phase in broccoli 'Fiesta' $F_{1}$ on 47 to 61 day from sowing, depending on the time of cultivation. It is possible that initiation of generative phase on a genetic and physiological level happened earlier during the ontogenesis and temperature of $2^{\circ} \mathrm{C}$ did not inhibit this process. Results of Diputado and Nichols (1989) confirm this observation. According to cited authors, the time to broccoli curd initiation appeared to be dependent on a heat unit summation above a base temperature of $1^{\circ} \mathrm{C}$ while the rate of curd growth was related best to a heat unit summation above $3^{\circ} \mathrm{C}$.

In a stage of harvest maturity, broccoli inflorescence consists of flower buds. Uniform size and shape of flower buds is one of the most important determinant of high market quality of curds (Björkman and Pearson, 1998; Dufault, 1996; Kałużewicz et al., 2009). Chilling temperature action in a seedling stage can affect the broccoli inflorescence development in different ways. When applied in early phase of growth, it can result in buttoning (Hadley and Pearson, 1998; Miller et al., 1985). In the conditions of presented experiment, dark-chilling of 4- to 10-weekold seedlings with $2^{\circ} \mathrm{C}$ for two weeks did not cased buttoning, but low temperature action on youngest seedlings positively influenced the inflorescence morphology. Curds of the best quality were developed by plants from 4-weekold seedlings, both chilled and control ones (Fig. 4 A-D).

Curds developed from 6-week-old non chilled (control) seedlings were also characterized by uniform formation of flower buds from all inflorescence branches, curds were dense. Chilling of 8- and 10-week-old seedlings resulted in worsening of curd quality. Curds were rough and scattered, flower buds were not uniform, bud stalks had differential length (Fig. 4E-H). The analysis of visual quality attributes of broccoli head showed the interaction of seedling age and chilling in modeling of bud diameter and bud stalk length (Tab. 1).

The flower buds of a greatest diameter were found in inflorescences developed from 4-week-old seedlings regardless of chilling, control 6-week-old seedlings and chilled 10 -week-old seedlings. Small and uniform flower buds in the inflorescence are the most desirable on a market. The head shape, bud color and bud diameter depended significantly only on the age of seedlings. The experimental factors did not affect the head diameter. The best market value characterized inflorescences developed from 4- and 6-week-old seedlings, because of convex head shape, tight branching angle, and dark green bud color. Basing on the presented results we recommended, that control chilling $\left(2^{\circ} \mathrm{C} / 2\right.$ weeks $)$ can be applied to 4 to 6 -week-old broccoli seedlings to enhance the visual quality of heads.
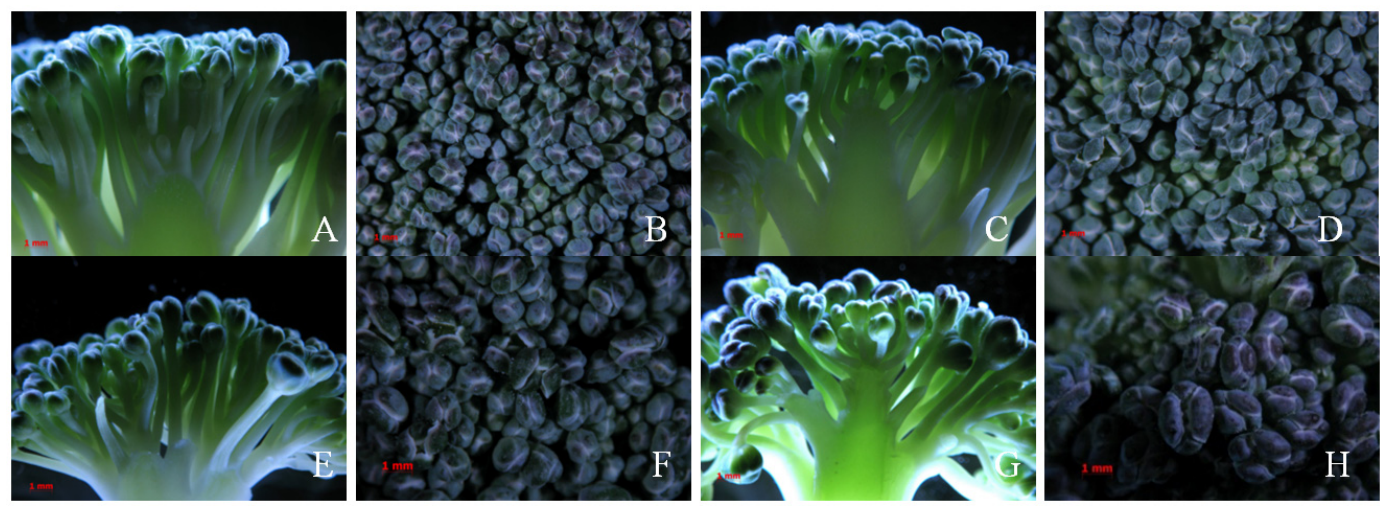

Fig. 4. The effect of seedling age and dark-chilling on flower buds formation in broccoli head: flower buds on the inflorescence developed by plant from 4-week-old control seedling (A, B), 4-week-old chilled seedling $(C, D), 10$-week-old control seedling $(E, F), 10$-week-old chilled seedling $(G, H)$ 
Tab. 1. The visual quality attributes of broccoli head as depended on the age of seedlings and dark-chilling, means for 2009 and 2010

\begin{tabular}{|c|c|c|c|c|c|}
\hline \multirow[b]{2}{*}{ Chilling time (weeks) } & \multicolumn{5}{|c|}{ Seedling age (weeks) } \\
\hline & 4 & 6 & 8 & 10 & Mean \\
\hline & \multicolumn{5}{|c|}{ Head diameter $(\mathrm{cm})$} \\
\hline 0 (control) & $27.3 \mathrm{a}^{*}$ & $27.1 \mathrm{a}$ & $27.6 \mathrm{a}$ & $26.4 \mathrm{a}$ & $27.1 \mathrm{~A}$ \\
\hline 2 & $28.1 \mathrm{a}$ & $27.5 \mathrm{a}$ & $27.3 \mathrm{a}$ & $26.4 \mathrm{a}$ & $27.3 \mathrm{~A}$ \\
\hline \multirow[t]{2}{*}{ Mean } & $27.7 \mathrm{~A}$ & $27.3 \mathrm{~A}$ & $27.4 \mathrm{~A}$ & $26.4 \mathrm{~A}$ & \\
\hline & \multicolumn{5}{|c|}{ Head shape (scale 1-5) } \\
\hline 0 (control) & $5.00 \mathrm{c}$ & $4.95 \mathrm{c}$ & $3.80 \mathrm{~b}$ & $2.87 \mathrm{a}$ & $4.16 \mathrm{~A}$ \\
\hline 2 & $5.00 \mathrm{c}$ & $5.00 \mathrm{c}$ & $3.67 \mathrm{~b}$ & $2.80 \mathrm{a}$ & $4.12 \mathrm{~A}$ \\
\hline \multirow[t]{2}{*}{ Mean } & $5.00 \mathrm{C}$ & $4.98 \mathrm{C}$ & $3.74 \mathrm{~B}$ & $2.84 \mathrm{~A}$ & \\
\hline & \multicolumn{5}{|c|}{ Branching angle (scale 1-5) } \\
\hline 0 (control) & $4.95 \mathrm{c}$ & $4.87 \mathrm{c}$ & $3.75 \mathrm{~b}$ & $2.85 \mathrm{a}$ & $4.11 \mathrm{~B}$ \\
\hline 2 & $4.97 \mathrm{c}$ & $4.87 \mathrm{c}$ & $3.55 \mathrm{~b}$ & $2.65 \mathrm{a}$ & $4.01 \mathrm{~A}$ \\
\hline \multirow[t]{2}{*}{ Mean } & $4.96 \mathrm{C}$ & $4.87 \mathrm{C}$ & $3.65 \mathrm{~B}$ & $2.75 \mathrm{~A}$ & \\
\hline & \multicolumn{5}{|c|}{ Bud colour (scale 1-5) } \\
\hline 0 (control) & $4.97 \mathrm{~b}$ & $4.87 \mathrm{ab}$ & $4.86 \mathrm{ab}$ & $4.77 \mathrm{a}$ & $4.87 \mathrm{~A}$ \\
\hline 2 & $4.95 \mathrm{ab}$ & $4.95 \mathrm{ab}$ & $4.84 \mathrm{ab}$ & $4.80 \mathrm{ab}$ & $4.89 \mathrm{~A}$ \\
\hline \multirow[t]{2}{*}{ Mean } & $4.96 \mathrm{C}$ & $4.92 \mathrm{BC}$ & $4.85 \mathrm{AB}$ & $4.79 \mathrm{~A}$ & \\
\hline & \multicolumn{5}{|c|}{ Bud diameter (mm) } \\
\hline 0 (control) & $1.37 \mathrm{ab}$ & $1.57 \mathrm{~b}$ & $1.20 \mathrm{a}$ & $1.22 \mathrm{a}$ & $1.34 \mathrm{~A}$ \\
\hline 2 & $1.50 \mathrm{~b}$ & $1.22 \mathrm{a}$ & $1.20 \mathrm{a}$ & $1.51 \mathrm{~b}$ & $1.36 \mathrm{~A}$ \\
\hline \multirow[t]{2}{*}{ Mean } & $1.46 \mathrm{C}$ & $1.37 \mathrm{BC}$ & $1.21 \mathrm{~A}$ & $1.32 \mathrm{AB}$ & \\
\hline & \multicolumn{5}{|c|}{ Bud stalk lenght (mm) } \\
\hline 0 (control) & $6.88 \mathrm{c}$ & $6.60 \mathrm{bc}$ & $5.84 \mathrm{ab}$ & $5.01 \mathrm{a}$ & $6.09 \mathrm{~B}$ \\
\hline 2 & $6.95 \mathrm{c}$ & $5.88 \mathrm{ab}$ & $5.07 \mathrm{a}$ & $5.04 \mathrm{a}$ & $5.74 \mathrm{~A}$ \\
\hline Mean & $6.92 \mathrm{C}$ & $6.24 \mathrm{~B}$ & $5.46 \mathrm{~A}$ & $5.03 \mathrm{~A}$ & \\
\hline
\end{tabular}

${ }^{*}$ Means with different letter are statistically different (Tukey, $\left.p \leq 0.05\right)$

\section{Conclusions}

The inflorescence initiation was observed between 4 and 6 week of the broccoli plant ontogeny. Chilling of 4and 6-week-old seedlings increased the percent of plants in next stages of a generative phase. Inflorescences developed by plants produced from 4- and 6-week-old seedlings, chilled and control, were characterized by the best visual quality, determined by a convex head shape, tight branching angle, small and uniform size and regular form of flower buds. Chilling of the oldest, 8- and 10-weekold seedlings negatively affected the quality of the heads, through planed and spread shape, and not uniform form of flower buds.

\section{Acknowledgements}

This work was supported by the Ministry of Science and Higher Education, Poland (DS 3500, 2010).

\section{References}

Bjorkman T, Pearson KJ (1998). High temperature arrest of inflorescence development in broccoli (Brassica oleracea var. italica L.). J Exp Bot 49:101-106.

Diputado MT, Nichols MA (1989). The effect of sowing date and cultivar on the maturity characteristics of broccoli (Brassica oleracea var. italica). Acta Hort 247:59-66.

Dufault RJ (1996). Dynamic relationships between field temperatures and broccoli head quality. J Amer Soc Hort Sci 121(4):705-710.

Fritz VA, Rosen CJ, Grabowski MA, Hutchison WD, Becker RL, Tong CBS, Wright JA, Nennich TT (2009). Growing broccoli, cabbage and cauliflower in Minnesota. University of Minnesota Extension Bulletin:1-15.

Fujime Y (1988). A difference of response to low temperature between cauliflower and broccoli. Acta Hort 218:141-152.

Fujime Y, Okuda N (1996). The physiology of flowering in Brassicas, especially about cauliflower and broccoli. Acta Hort 407:247-254.

Grabowska A, Kunicki E, Libik A (2007a). Effects of age and cold storage of transplants on the growth and quality of broccoli yield. Veg Crops Res Bull 66:31-38.

Grabowska A, Kunicki E, Libik A (2007b). The effect of transplants age and storage time in a cold room on chemical composition of broccoli heads. Folia Hort 19(2):11-22.

Grevsen K (1998). Effects of temperature on head growth of broccoli (Brassica oleracea L. var. italica): Parameter estimates for a predictive model. J Hort Sci Biotechnol 73(2):235244. 
218

Grevsen K, Olesen JE (1999). Modeling development of broccoli (Brassica oleracea L. var. italica) from transplanting to head initiation. J Hort Sci Biotechnol 74(6):698-705.

Hadley P, Pearson S (1998). Effects of environmental factors on progress to crop maturity in selected Brassica crops. Acta Hort 459:61-70.

Kałużewicz A, Kordakow J, Czosnowski E, Knaflewski M (2002). Effect of thermal conditions on the initiation of broccoli curd. El J Pol Agric Univ 5(2):1-8.

Kałużewicz A, Krzesiński W, Knaflewski M (2009). Effect of temperature on the yield and quality of broccoli heads. Veg Crops Res Bull 71:51-58.

Kałużewicz A, Krzesiński W, Knaflewski M, Lisiecka J, Spiżewski T, Frąszczak B (2010). The effect of temperature on the broccoli yield and length of the period from head initiation to harvest. Acta Sci Pol Hortorum Cultus 9(3):167-174.

Masarirambi MT, Oseni TO, Shongwe VD, Mhazo N (2011). Physiological disorders of Brassicas/Cole crops found in Swaziland: A review. African J Plant Sci 5(1):8-14.

Miller CH, Konsler TR, Lamont WJ (1985). Cold stress influence on premature flowering of broccoli. HortSci 20(2):193195.
Mourao IM, Brito LM (2000). Empirical models for harvest date prediction in broccoli (Brassica oleracea L. var. italica Plenck). Acta Hort 539:47-53.

Tan DKY, Birch CJ, Wearing AH, Rickert KG (2000). Predicting broccoli development. I. Development is predominantly determined by temperature rather than photoperiod. Sci Hort 84(3-4):227-243.

Tan DKY, Wearing AH, Rickert KG, Birch CJ (1998). Detection of floral initiation in broccoli (Brassica oleracea L. var. italica Plenck) based on electron micrograph standards of shoot apices. Australian J Exp Agric 38(3):313-318.

Tan DKY, Wearing AH, Rickert KG, Birch CJ (1999). Broccoli yield and quality can be determined by cultivar and temperature but not photoperiod in south-east Queensland. Australian J Exp Agric 39:910-909.

Wurr DCE, Akehurst JM, Thomas TH (1981). A hypothesis to explain the relationship between low-temperature treatment, gibberellin activity, curd initiation and maturity of cauliflower. Sci Hort 15(4):321-330. 